\section{Commentary: Grafting the occluded right coronary artery: The sunny side of the street}

\author{
Erin M. Schumer, MD, MPH, and \\ Phillip G. Rowse, MD
}

Chronic total occlusions (CTOs) are a common finding in patients with coronary artery disease (CAD) and are often associated with older age, advanced medical comorbidities (ie, stroke and renal impairment), and reduced ejection fraction. Management of CTOs at the time of surgical revascularization for multivessel CAD can be challenging due to small vessel size, severe calcification, ischemic burden, and lack of collateralization, as well as the uncertainty of long-term graft patency. Specific aspects of CTO revascularization include influence on quality of life and survival. Contemporary studies have documented improved freedom from major adverse cardiac events with successful bypass of CTO lesions involving the left anterior descending coronary artery. ${ }^{1}$ However, the benefit non left anterior descending coronary artery CTO revascularization is less certain.

Fiddicke and colleagues ${ }^{2}$ present a single institution, 10year retrospective analysis of 587 consecutive patients who underwent coronary artery bypass (CABG) operation with the preoperative diagnosis of multivessel $\mathrm{CAD}$ that included a CTO of the right coronary artery (RCA). The authors reported on 2 groups of patients: 487 patients who underwent $\mathrm{CABG}$ that included revascularization of the CTO RCA (Group 1) and 100 patients who did not have the CTO RCA grafted at the time of surgery (Group 2). Postsurgical outcomes of major adverse cardiac and cerebrovascular events were analyzed with follow-up extended to 6 years. Whilst in-hospital mortality was comparable $(2.9 \%$ in Group 1 vs $5.0 \%$ in Group $2 ; P=.27)$, long-

From the Department of Cardiovascular Surgery, Mayo Clinic, Rochester, Minn. Disclosures: The authors reported no conflicts of interest.

The Journal policy requires editors and reviewers to disclose conflicts of interest and to decline handling or reviewing manuscripts for which they may have a conflict of interest. The editors and reviewers of this article have no conflicts of interest.

Received for publication June 25, 2021; revisions received June 25, 2021; accepted for publication June 29, 2021; available ahead of print July 15, 2021.

Address for reprints: Phillip G. Rowse, MD, Department of Cardiovascular Surgery, Mayo Clinic, 200 First St, SW, Rochester, MN 55905 (E-mail: Phillip.rowse@ mayo.edu).

JTCVS Open 2021;7:180-1

2666-2736

Copyright (C) 2021 The Author(s). Published by Elsevier Inc. on behalf of The American Association for Thoracic Surgery. This is an open access article under the CC BY-NC-ND license (http://creativecommons.org/licenses/by-nc-nd/4.0/).

https://doi.org/10.1016/j.xjon.2021.06.023

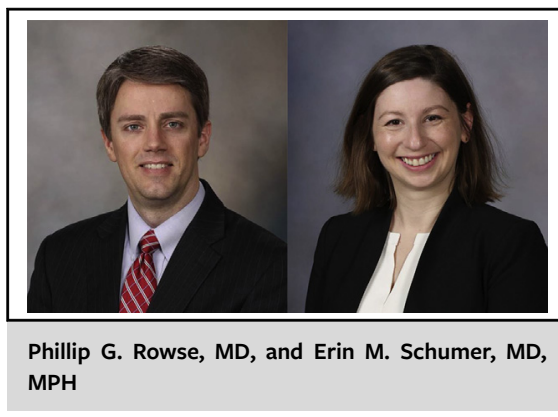

CENTRAL MESSAGE

Revascularization of chronically occluded RCAs at the time of multivessel CABG may improve survival.

term survival was significantly better in Group 1 than in Group 2. Additionally, there was no observable difference in the incidence of major adverse cardiac and cerebrovascular events between the study groups. Analysis of this article hoped to elucidate a survival benefit when a chronically occluded native RCA was bypassed at the time of CABG.

The major strengths of the article are the inclusion of a control group with moderately long follow-up and risk adjustment in the survival analysis. The potential weakness of the study includes its retrospective observational design, heterogeneous comparative groups, and possible selection bias during CTO grafting. Furthermore, whereas the association between nongrafting of a severely diseased coronary territory and worse outcome is somewhat intuitive, it may be difficult to conclude how much of this association is causal.

Although the comparison results between the 2 groups would be more convincing if it were known that all patients in the nongrafted CTO RCA group had graftable targets and did not receive one, the authors nonetheless make a clarion call against therapeutic nihilism often associated with revascularization of CTO lesions. Strauss and colleagues ${ }^{3}$ also concede a zeal for surgical revascularization of CTO RCA targets without any untoward morbidity; however, long-term benefit was not demonstrated.

In summary, the authors have evaluated the consequence of revascularizing, or not, known CTO RCA lesions among patients who underwent multivessel CABG. Although the results of the study are intriguing, with improved survival favoring revascularization of CTO RCA lesions, more definitive data supporting this finding will likely need to come by way of a prospective, randomized study. 


\section{References}

1. Zakkar M, George SJ, Ascione RS. Should chronic total occlusion be treated with coronary artery bypass grafting? Chronic total occlusion should be treated with coronary artery bypass grafting. Circulation. 2016;133: 1807-16.

2. Fiddicke M, Fleissner F, Brunkhorst T, Kühn EM, Obed D, Boethig D, et al. Coronary artery bypass grafts to chronic occluded right coronary arteries. J Thorac Cardiovasc Surg Open. 2021;7:169-79.

3. Strauss BH, Shuvy M, Wijeysundera HC. Revascularization of chronic total occlusions: time to reconsider? J Am Coll Cardiol. 2014;64:1281-9. 